\title{
Ito stellate cells (hepatic stellate cells) in diagnosis of liver fibrosis
}

\section{Introduction}

Adverse outcome of most chronic diffuse liver lesions of various etiologies including chronic hepatitis $\mathrm{C}(\mathrm{CHC})$ is liver fibrosis in the development of which main participants are activated fibroblasts. Activated hepatic stellate cells (HSC) are the main source of activated fibroblasts. ${ }^{1,2}$

HSC, a synonym - stellate cells of liver, Ito cells, perisinusoidal lipocytes, stellate cells. HSC were firstly described in 1876 and named by K. Kupffer stellate cells T. Ito, finding in them a drop of fat firstly marked them as lipophagic («shibo-sesshusaibo») but then finding that the fat elaborated by the cells from glycogen named them as fat-storing cells or Ito sells («shibo-chozosaibo»). ${ }^{3}$ In 1971, K. Wake proved the identity of stellate cells of Kupffer and Ito cells and that these cells are "stored" vitamin A. ${ }^{4}$

About $80 \%$ of vitamin A which is in the body accumulates in the liver and up to $80 \%$ of liver retinoids deposited in fat droplets of HSC. Ethers of retinol in formulation of chylomicrons entered to hepatocytes, where they are converted to retinol and form of vitamin A complex with retinol binding protein (RBP), which is secreted in perisinusoidal space where it deposited by cells. ${ }^{5}$

Established by K. Popper close relationship of HSC with the hepatic fibrosis demonstrated theirs not static, but dynamic function. It means the ability to be directly involved in the remodeling of intralobular perihepatocellular matrix. ${ }^{6}$ The main method of morphological study of liver conducted by assessing the changes in lifetime biopsy materials is light microscopy. This method in clinical practice allows establishing the stage of inflammation activity and stage of chronization. ${ }^{7}$ The disadvantage of this method is low resolution which does not allow evaluating features of cell structure, intracellular organelles, insertions, functional characteristics. Lifetime electron-microscopic study of ultrastructural changes in the liver makes it possible to supplement the light microscopy data and raise their diagnostic value.

In this regard the identification of the HSC, study of their phenotype during transdifferentiation and determining the intensity of their proliferation are the major contribution to the prediction of outcomes of liver disease as well as in the patomorphology and pathophysiology of fibrogenesis. The aim of research is to introduce structural and functional description of HSC on the results of cytological identification of lifetime liver biopsies.

Abbreviations: $\mathrm{CD}$, cluster of differentiation; $\mathrm{CHC}$, chronic hepatitis $\mathrm{C}$; HCV, hepatitis $\mathrm{C}$ virus; HSC, hepatic stellate cells; ICAM, intercellular adhesion molecule; MMPs, matrix metaloproteinases; PDGF, platelet-derived growth factor; RBP, retinol-binding protein; RER, rough endoplasmic reticulum; TIMPs, tissue inhibitors of matrix metaloproteinases
Volume 10 Issue 4 - 2019

\author{
Vladimir Tsyrkunov, ' Viktor Andreev, ${ }^{2}$ Rimma \\ Kravchuk, ', Iryna Kandratovich' \\ 'Department of Infectious Diseases, Grodno State Medical \\ University, Belarus \\ ${ }^{2}$ Department of Histology, Grodno State Medical University, \\ Belarus \\ ${ }^{3}$ Department of Science, Grodno State Medical University, \\ Belarus
}

Correspondence: Iryna Kandratovich, Department of Infectious Diseases, Grodno State Medical University, Gorkogo str 80, Grodno 230009, Belarus, Tel +375I52434286, Fax +375152434286, Email iriskak22@mail.ru

Received: October 29, 2018 | Published: July 25, 2019

\section{Methods}

Lifetime liver biopsy obtained by performing aspiration biopsy of the liver of patients with $\mathrm{CHC}$ (HCV ribonucleic acid + ). Patients gave theirs written informed consent. For light microscopy semifine sections of liver biopsy samples of patients $0,5 \times 2 \mathrm{~mm}$ in size were fixed by double fixation method: firstly by the Sato Taizan technique. ${ }^{8}$ Then tissue samples for 1 hour additionaly fixed in $1 \%$ osmium fixative prepared with $0.1 \mathrm{M}$ phosphate buffer of Zerensen, $\mathrm{pH}$ 7.4. For better identification of intracellular structures and interstitial substance on semifine sections in $1 \%$ osmium tetroxide was added potassium dichromate (K2Sr2O7) or crystals of chromic anhydride $(1 \mathrm{mg} / \mathrm{ml})$. After dehydration of samples in series of alcoholic solutions of increasing concentrations and acetone they were placed in the prepolymerized mixture of butyl methacrylate and styrole and polymerizing at $55^{\circ} \mathrm{C}$. Semifine sections (thickness of 1 microeter) were sequentially stained with azure II-basic fuchsine. Microphotographies obtained with using of digital video camera (Leisa FC 320, Germany).

Electron-microscopic study was performed in samples of liver biopsy materials $0,5 \times 1,0 \mathrm{~mm}$ in size fixed with $1 \%$ osmium tetroxide

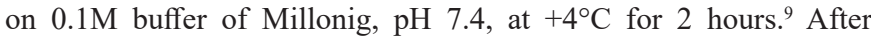
dehydration in alcohols of increasing concentrations and acetone samples were embedded in Araldite. ${ }^{10,11}$ From these blocks on ultramicrotome Leica EM VC7 (Germany) were prepared semifine sections $(400 \mathrm{~nm})$ and stained with methylene blue. Specimens viewed under the light microscope and the same type of site chosen for further study of ultrastructural changes. Ultrathin sections $(35 \mathrm{~nm})$ contrasted with $2 \%$ solution of uranyl acetate per $50 \%$ of methanol ${ }^{12}$ and lead citrate by E.S. Reynolds. ${ }^{13}$ Electron-microscopic spesimens were studied in the electron microscope JEM-1011 (JEOL, Japan) with an increase of 10000-60000 at an accelerating voltage of $80 \mathrm{~kW}$. 
For images was used a set of digital camera Olympus MegaViewIII (Germany) and programs for processing of images iTEM (Olympus, Germany).

\section{Results and discussion}

HSC located in perisinusoidal space (Disse) in recesses between hepatocytes and endotheliocytes and have long processes that penetrate deep between hepatocytes. In the majority of publications devoted to this population of HSC is a schematic representation of them which allows only indication of "territorial" belonging of HSC in the liver and in relation to others of their "neighbors" (Figure 1).

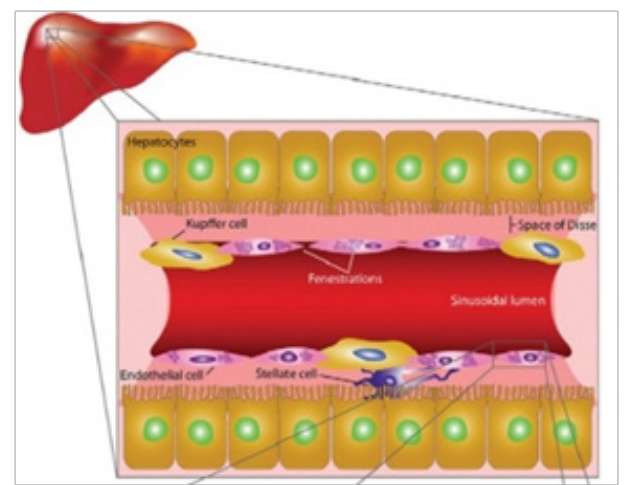

Figure I Diagram of HSC location in perisinusoidal space of Disse, an internete resource.

HSC have close contact with endotheliocytes through the incomplete basement membrane components and interstitial collagen fibers. Nerve endings penetrate between HSC and parenchymatous cells, wherefore the space of Disse defines as the space between the plates of parenchymatous cells and HSC complex and endotheliocytes. ${ }^{14}$

It is supposed that HSC become from poorly differentiated mesenchymal cells transverse septum of developing liver. ${ }^{15}$ The experiment revealed that in the formation of HSC hematopoietic stem cells participates, and that this process is not caused by cell fusion. ${ }^{16}$

Sinusoidal cells, first of all HSC, play a leading role in all forms of liver regeneration. Fibrotic liver regeneration occurs as a result of the inhibition of HSC stem functions and stem cells of marrow. ${ }^{17}$ In human liver HSC constitute $5-15 \%$ being one of 4 types of sinusoidal cells with mesenchymal origin: Kupffer cells, endotheliocytes and Pit-cells. Within pool of sinusoidal cells $20-25 \%$ of leukocytes are detected. $^{18,19}$

There are lipid inclusions with retinol, triglycerides, phospholipids, cholesterol, free fatty acids, a-actin and desmin in the cytoplasm of HSC. ${ }^{20}$ To visualize HSC auric chloride staining is used. The experiment found that differentiation marker of HSC from other myofibroblasts is the expression by them protein reelin. ${ }^{21}$

HSC exist in a stable - "inactive HSC", transitional and long-term active condition, each of which is characterized by genes expression and the phenotype (alpha-smooth muscle actin, intercellular adhesion molecule (ICAM)-1, chemokines and cytokines).

HSC in stable condition are round, slightly elongated or irregular shape, large nucleus and vivid imaging feature - lipid inclusions (droplets) containing retinol (Figure 2).
The amount of lipid droplets in the inactive HSC is 30 or more.

They are similar in size and are adjacent to each other, pressing into the nucleus and pushing it aside periphery (Figure 2). Small inclusions can be placed between large droplets. The color of droplets depends on the fixator and staining of material. In one case, they are bright (Figure 2A), in the other they are dark green (Figure 2B).

At electron microscopy on a background of the light lipidic substrate more osmiophil marginal ring is formed (Figure 2C). ${ }^{22}$ Most of the "inactive" HSC along with large lipid inclusions small amount of cytoplasmic matrix poor on mitochondria and rough endoplasmic reticulum (RER) is seen. However, compartments of moderately developed Golgi complex in the form of stacks of 3-4 flattened cisterns with slightly extended ends are clearly seen (Figure $2 \mathrm{~S}$ ).
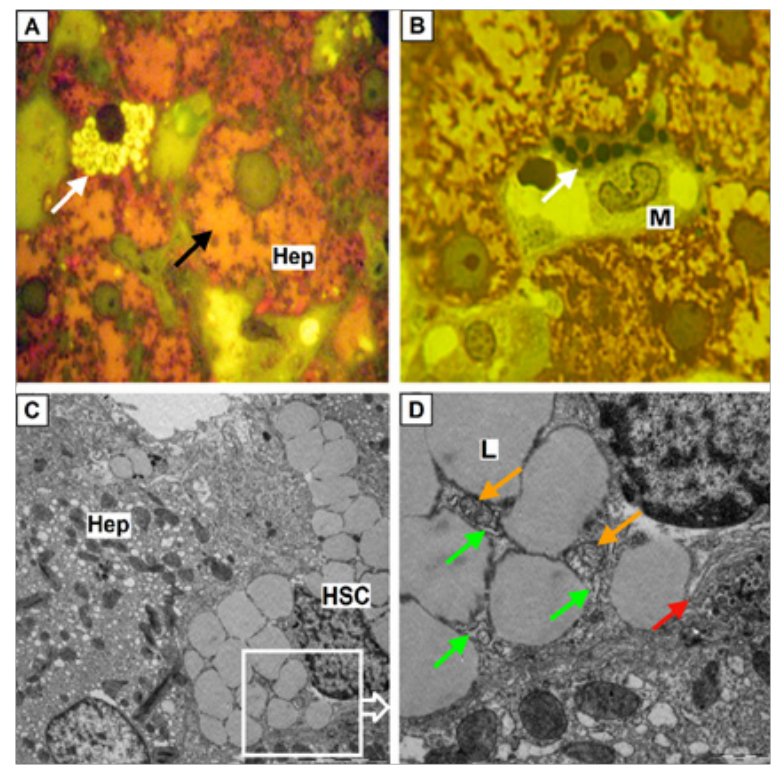

Figure 2 HSC which are in inactive condition.

(A) Hepatic stellate cells (HSC) of round shape with a high content of lipid droplets with a light color (white arrows), hepatocytes (Hep) with the devastated cytoplasm (black arrow); B, HSC with lipid droplets of dark color (white arrows), in close contact with macrophage (M); A, B, Semifine sections, stained with azure II - basic fuchsine, microphotography, zoom 1000; C, HSC with plenty of lipid droplets (more then 30 ) having an irregular shape, zoom 6000 (Hep - hepatocyte); D, Ultrastructural components of HSC: lipid droplets (L), mitochondria (orange arrow), rough endoplasmic reticulum (green arrows), the Golgi complex (red arrow), zoom I5000; (C-D) Electron diffraction patterns.

Under certain conditions activating HSC obtain mixed or transitional phenotype combining morphological characteristics of lipid like and fibroblast-like cells (Figure 3). ${ }^{22}$

The transitional phenotype of HSC also has its morphological features. The cell becomes elongated shape, the number of lipid inclusions decreases and there is a reduction of intussusception of nuclear envelope. The volume of the cytoplasm containing numerous cisterns of RER with related ribosomes and free ribosomes and mitochondria is increasing. There is hyperplasia of lamellar Golgi complex components' represented by multiple stacks of 3-8 flattened cisterns and the number of lysosomes involved in degradation of lipid droplets is increasing (Fig. 3D). Hyperplasia components of RER and Golgi complex associated with ability of fibroblasts to synthesize 
collagen molecules, as well as to simulate them by post-translational hydroxylation and glycosylation in the endoplasmic reticulum and Golgi complex elements.
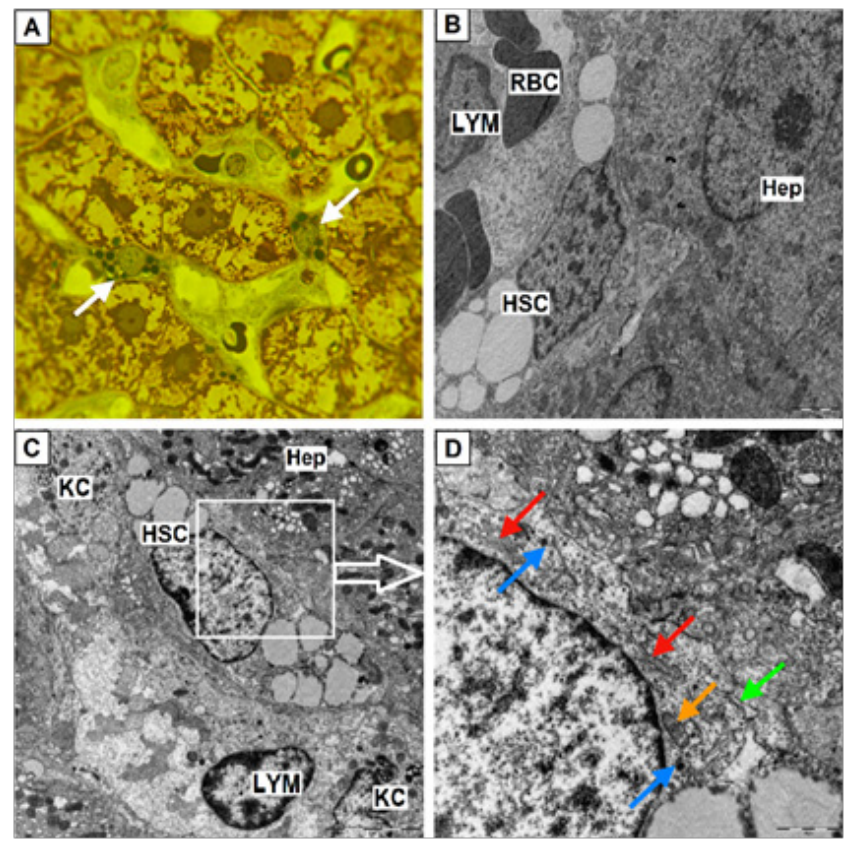

Figure $3 \mathrm{HSC}$ are there in the transitional state.

Hepatic stellate cells (HSC) (white arrows), semifine sections, stained with azure II - basic fuchsine, microphotography, zoom 1000; B, HSC of elongated shape and a small amount of lipid droplets, zoom 8000 (Hep - hepatocyte, RBC - red blood cell, LYM - lymphocyte ); C, HSC in contact with Kupffer cells (KC) and lymphocyte (LYM), zoom 6000 (Hep - hepatocyte); D, Mitochondria (orange arrow), rough endoplasmic reticulum (green arrows), the Golgi complex (red arrow), lysosomes (blue arrows), zoom 20 000; B, C, $D$, Electron diffraction patterns.

In the intact liver HSC while at rest cover by their processes sinusoidal capillary. Processes of HSC divided into 2 types: perisinusoidal (subendothelial) and interhepatocellular (Figure 4).

Perisinusoidal (subendothelial) processes out of the cells' body and extend along the surface of sinusoidal capillary covering it by thin digitiform rami. They are covered with short villi and have characteristic long micro-emissions extending even further on the surface of endothelial capillary tube. Interhepatocellular outgrowths, breaking the lamella of hepatocytes and attaining neighboring sinusoid are divided into several perisinusoidal outgrowths. Thus, HSC on average cover over two adjacent sinusoids. ${ }^{23}$

When liver damages then activation of HSC and fibrogenesis occur which distinguish 3 phases. They are designated as the initiation, prolongation and the resolution (resolution of fibrous tissue). ${ }^{24}$ This process of transformation of the "stable" HSC in fibrosing myofibroblasts is activated by cytokines (interleukin-1, interleukin-6, tumor necrosis factor alpha), insufficiently oxidized products of metabolism, active form of oxygen, nitric oxide, endothelin, plateletderived growth factor (PDGF), plasminogen activator, transforming growth factor $\beta-1$, acetaldehyde and others. Direct activators are hepatocytes in state of oxidative stress, Kupffer cells, endotheliocytes, leukocytes, platelets which produce cytokines (paracrine signals) and HSC themselves (autocrine stimulation). The activation is accompanied by the expression (inclusion in work) of new genes, the synthesis of cytokines and extracellular matrix proteins (collagen I, III, V type). ${ }^{25,26}$

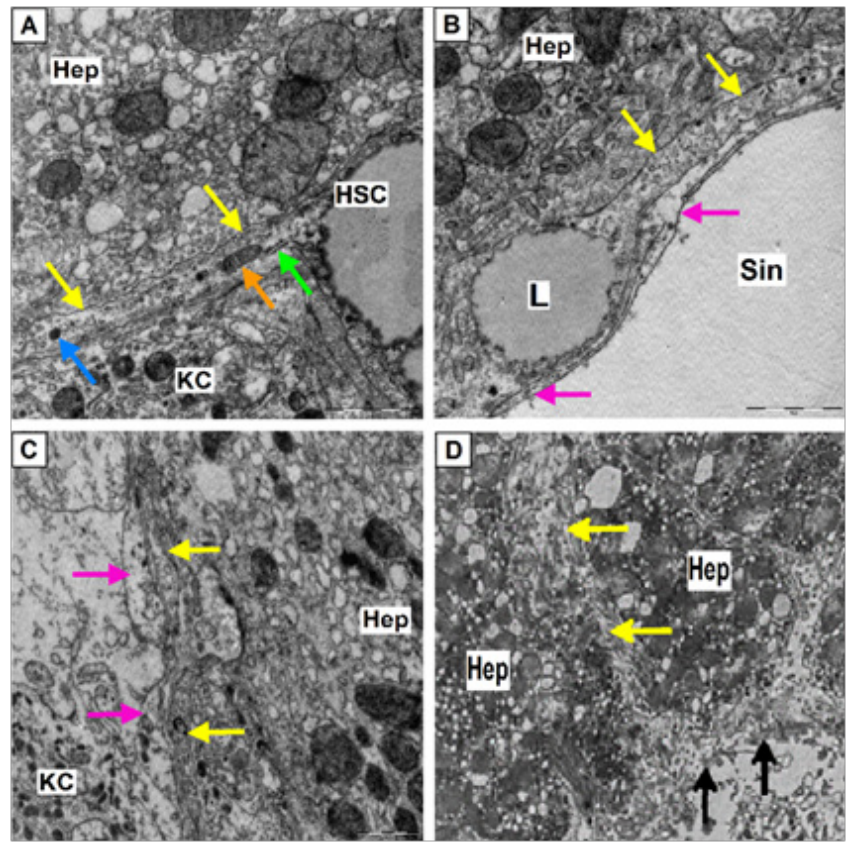

Figure 4 Perisinusoidal (subendothelial) and interhepatocellular processes (outgrowth) of HSC.

(Hep - hepatocyte, KC - Kupffer cells, mitochondria-orange arrow, rough endoplasmic reticulum-green arrows, lysosomes - blue arrows, processes of endothelial cells -pink arrows).

(A) Process of hepatic stellate cells (HSC) (yellow arrows) coming from the cell body, zoom 30 000; (B) Process of HSC (yellow arrows), located along the surface of sinusoidal capillary (Sin) containing lipid droplet $(\mathrm{L})$, zoom 30 000; (C) Subendothelial located processes of HSC (yellow arrows); (D) Interhepatocellular process of HSC (yellow arrows), area of membrane destruction of HSC and hepatocyte (black arrows), zoom $10000 ; A-D$, electron diffraction patterns.

At this stage the process of HSC activation can be completed due to the stimulation of formation in HSC antiinflammatory cytokines inhibiting tumor necrosis factor alpha production by macrophages in the damage zone. As a result, the amount of the HSC is sharply reduced, they undergo apoptosis and processes of fibrosis in the liver do not develop..$^{27,28}$

At the second phase (prolongated) during prolonged continuous paracrine and autocrine influence of activating stimuli in the HSC "supported" an activated phenotype characterized by the transformation of HSC in contractile myofibroblast-like cells which realize synthesis of extracellular fibrillar collagen.

The activated phenotype is characterized by proliferation, chemotaxis, contractility, loss of retinoid reserves and formation of cells which are myofibroblast-like. ${ }^{29}$ Activated HSC also demonstrate high content of new genes such as alpha-smooth muscle actin, ICAM1 , chemokines and cytokines. Cell activation indicates the beginning of the early stage of fibrogenesis and precedes increased production of extracellular matrix proteins. ${ }^{30}$ Formed fibrous tissues undergo remodeling due to the splitting of the matrix with help of matrix 
metaloproteinases (MMPs). In turn, splitting of matrix is regulated by tissue inhibitors of MMPs (TIMPs). MMPs and TIMPs are part of a family of zinc-dependent enzymes. MMPs are synthesized as inactive HSC proenzymes which are activated by removal of propeptide, but inhibited by interaction with endogenous TIMPs - TIMPs-1 and TIMPs-2. HSC produce 4 types of membrane-type MMPs which are activated by influence interleukin-1. Among MMPs particular importance is attached to MMPs-9 - neutral matrixmetaloproteinase which has activity against collagen of type 4 , which is the part of basal membrane, as well as against partially denatured collagens 1 st and 5 th types. ${ }^{30-32}$

About the increase in population of HSC in various liver damage is judged by an activity of significant number of mitogenic factors, related to them tyrosine kinase receptors and other identified mitogens, which cause the most pronounced proliferation of HSC: endothelin-1, thrombin, fibroblast growth factor, PDGF, insulin-like growth factor. The accumulation of HSC in areas of damaged liver occurs not only due to the proliferation of these cells, but also due to their directional migration to these areas by chemotaxis, with the participation of such chemoattractants, as PDGF and leukocyte chemoattractant monocyte chemotactic protein- $1 .{ }^{24,32}$

At activated HSC number of lipid droplets is reduced to 1-3 with their location on opposite poles of the cell (Figure 5).
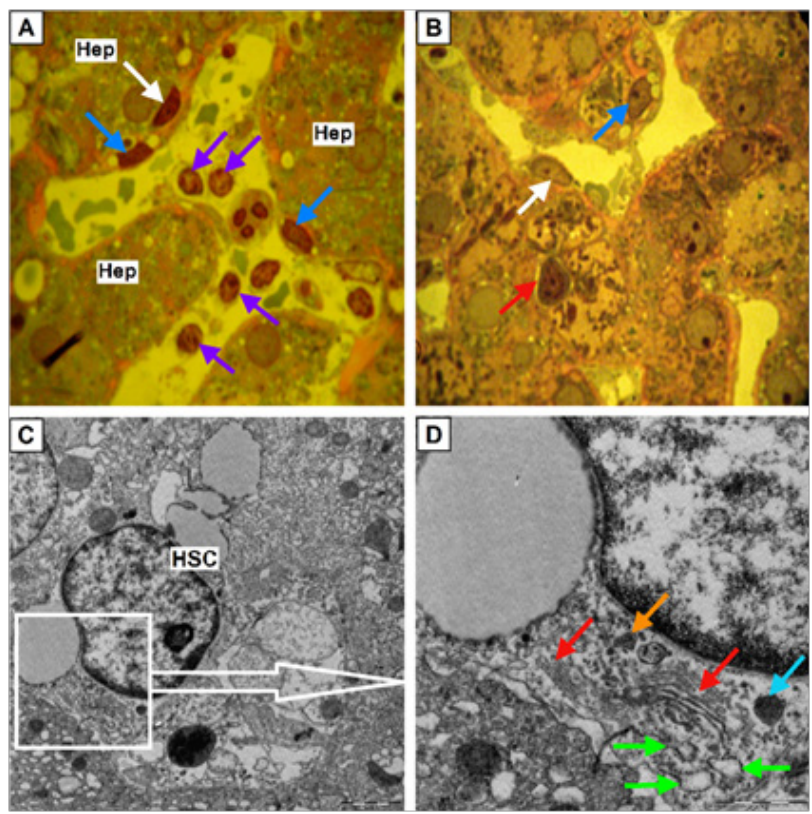

Figure 5 HSC which are in active condition.

(A,B) Hepatic stellate cells (HSC) (blue arrows) with a single lipid inclusion localized at the opposite poles of nucleus. Perisinusoidal connective tissue (Figure 5A) and interlayer of intercellular matrix around hepatocyte (Figure5 B) stained red. Cytotoxic lymphocytes (purple arrows). Endotheliocyte (white arrow). Close contact of plasma cells (red arrow) and hepatocyte (Hep). Semifine sections, stained with azure II - basic fuchsine, microphotography, zoom 1000

(C,D) Ultrastructural components of HSC: mitochondria (orange arrow), the Golgi complex (red arrow), cisterns of it more osmiophil cis-side facing to widen elements of rough endoplasmic reticulum (green arrows), lysosome (blue arrow). Zoom 10000 and 20000 respectively, electron diffraction patterns.
Activated HSC obtained an elongated form, large areas of cytoplasm occupies the Golgi complex, and revealed quite numerous cisterns of RER (index of protein synthesis for export). Number the rest of organelles is reduced: found small free ribosomes and polysomes, mitochondria and irregularly - lysosomes (Figure 6).
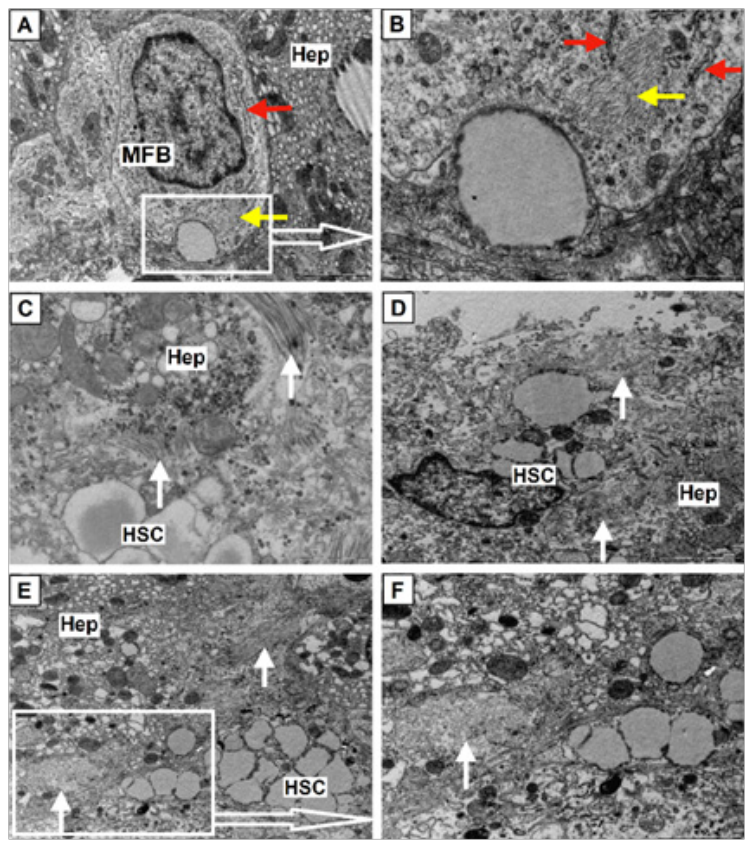

Figure 6 High fibrotic activity of HSC.

(A-B) Myofibroblasts (MFB), the cell contains large nucleus, elements of rough endoplasmic reticulum (red arrows), numerous free ribosomes, polymorphic vesicles and granules, single mitochondria and bright imaging feature - a bundle of actin filaments in cytoplasm (yellow arrows), zoom 12000 and 40000 (Hep - hepatocyte); (C-F) High fibrotic activity of Hepatic stellate cells (HSC) while maintaining at cytoplasm retinoid containing lipid droplets. Numerous bundles of collagen fibrils (white arrows), save (C) and lost (D-F) specific cross striation; zoom $25000,15000,8000$, 15000 , electron diffraction patterns.

In 2007 for the first time HSC were named as liver stem cells since they express one of the markers from a hematopoietic mesenchymal stem cells - cluster of differentiation (CD)-133. ${ }^{33}$

Myofibroblasts which are absent in normal liver have three potential sources: the first - at intrauterine liver development in portal tracts myofibroblasts surround blood vessels and bile ducts during their maturation and after the full development of the liver they disappear and are replaced in the portal tracts by portal fibroblasts; the second - with the damaging of liver they are formed due to the portal mesenchymal cells and resting HSC. Sometimes they are formed due to expense of the transitional epithelial-mesenchymal cells. They are characterized by the presence of CD45-, CD34-, Desmin+, glial fibrillary acidic protein + and Thy-1+.

Recent studies have shown hepatocytes, cholangiocytes, and endothelial cells can become myofibroblast through epithelialor endothelial-mesenchymal transition. These cells include such markers as CD45-, albumin + (i.e. hepatocytes), CD45-, CD19+ (i.e. cholangiocytes) or Tie2+ (endothelial cells). In addition, marrow cells consisting of fibrocytes and circulating mesenchymal cells may transform into myofibroblasts. These cells are CD45 + (fibrocyte), CD45 +/- (circulating mesenchymal cells), collagen type I+, CD11d+ and major histocompatibility complex, class II+ (Figure 7). ${ }^{2,15}$ 


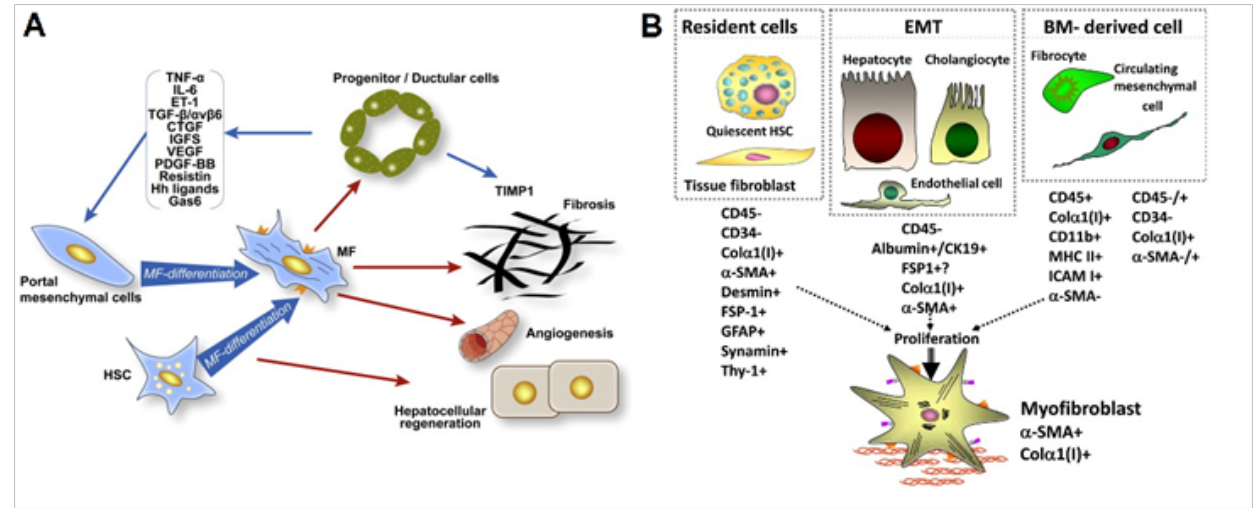

Figure 7 Participants of miofibroblastic activation of HSC.

(A) Interaction of ductal hepatic precursor cells with myofibroblasts of liver; activation. ${ }^{34,35}$

Literature data confirm not only the close relationship proliferation of oval cells with proliferation of sinusoidal cells, ${ }^{36,37}$ but also the data about possible differentiation of HSC in the hepatic epithelium ${ }^{38}$ which was called epithelial-mesenchymal transformation of perisinusoidal cells. $^{39}$

In the state of fibrogenic activation miofibroblast-like HSC along with decrease the number and following disappearance of lipid droplets characterized by nodal proliferation (Figure 8), the immunohistochemical expression of fibroblast-like markers including smooth muscle $\alpha$-actin and formation of pericellular collagen fibrils in the space of Disse. ${ }^{34,35}$
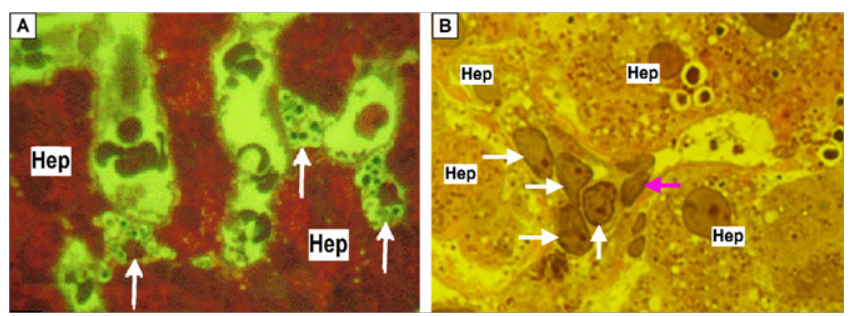

Figure 8 Nodal proliferation of HSC in condition of fibrogenic activation.

(A) Hepatic stellate cells (HSC) hyperplasia (white arrows) in the lumen of dilated sinusoids (Hep - hepatocyte); (B) Proliferation of transdifferentiational HSC (white arrows), endothelial cell (pink arrow). (A,B) Semifine sections, stained with azure II - basic fuchsine, microphotography, zoom 1000.

In phase of fibrosis increasing hypoxia of liver tissue becomes a factor of additional surplus expression in stem cells of proinflammatory adhesion molecules - ICAM-1, ICAM-2, vascular endothelial growth factor, pro-inflammatory chemoattractants monocyte colony stimulating factor, monocyte chemotactic protein-1 and cytokine-induced neutrophil chemoattractant and others that stimulate the formation of pro-inflammatory cytokines (transforming growth factor $\beta-1$, PDGF, fibroblast growth factor, PAF, SCF, ET-1) and strengthen the processes of fibrogenesis in the liver creating the conditions for a self-supporting induction, ongoing activation of HSC and process of fibrogenesis. ${ }^{32}$

On microscopic specimens pericapillary fibrosis displays as intense color of perisinusoidal connective tissue and layer of intercellular matrix surrounding hepatocytes (they are often die) in red. At the electron microscopic specimens fibrotic changes visualized either in the form of formed large fascicles of fibrils of collagen fibers preserved diametrical bending, or in the form of massive deposits in the Disse space of fiber mass, which is a swollen and lost periodic banding of collagen fibers (Figure 9).
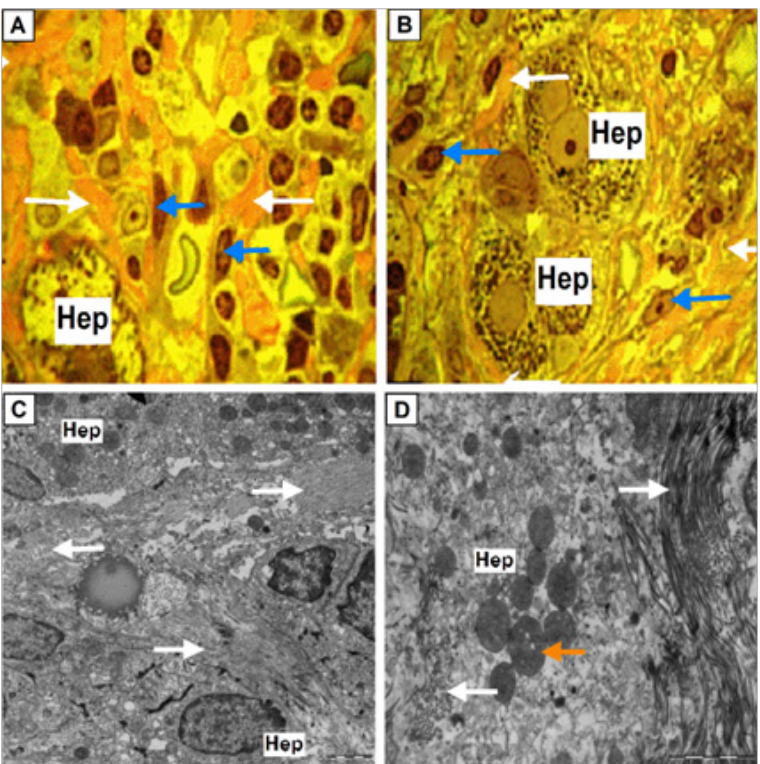

Figure 9 The final stage of miofibroblastic activation of HSC.

(A-B) Perisinusoidal fibrosis (white arrows). Perisinusoidal connective tissue and layer of intracellular matrix surrounding hepatocytes (Hep) stained with basic fuchsine in red. Hepatic stellate cells (HSC) activated and transformed in fibroblasts (blue arrows). Hepatocyte at picture A - hepatocyte with devastated cytoplasm. Semifine sections, stained with azure II - basic fuchsine, microphotography, zoom 1000.

(C-D) Perisinusoidal and perihepatocellular fibrosis in the liver lobule, increased electron density of fibril collagen fibers; condensation of matrix of mitochondria in hepatocyte (orange arrow). Zoom 8000 and 15000 respectively, electron diffraction patterns. 
According to modern concepts fibrosis is a dynamic process that can progress and regress (Figure 10). Recently, several specific markers of HSC have been proposed: the rise of vitamin A in lipid droplets, glial fibrillary acidic protein, nerve growth factor receptor and synaptophysin. ${ }^{25,41}$ Researches on participation of liver HSC in proliferation and differentiation of stem cells of the liver are taken. ${ }^{15,16}$ We studied level of retinol and the content of RBP4 at blood serum. RBP4 forms a complex with retinol and whose concentration in blood plasma correlates normally with the body's provision of vitamin A, $80 \%$ of which is in the HSC (Table 1 ).
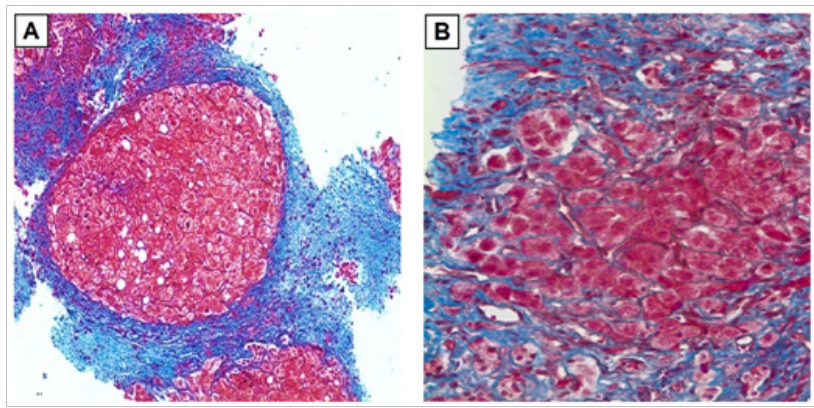

Figure I 0 Dynamic of events in the pseudolobule of patient with viral cirrhosis of liver 6 months after transplantation in liver autologous mesenchymal stem cells. ${ }^{40}$ (A) Pseudolobules surrounded by fibrous septa, staining by Masson, zoom 50; (B) Resolution of fibrous septa around pseudolobules, staining by Masson, zoom 200.

Table I Indicators of retinol-binding protein 4 and vitamin A content in patients with liver cirrhosis and chronic hepatitis of various etiologies

\begin{tabular}{|c|c|c|c|c|c|}
\hline \multirow[t]{2}{*}{ Group } & \multirow[t]{2}{*}{$\mathbf{n}$} & \multicolumn{2}{|c|}{ RBP4, ng/ml } & \multicolumn{2}{|l|}{$\begin{array}{l}\text { Vitamin A, } \\
\text { mcmole/l }\end{array}$} \\
\hline & & $M \pm m$ & $\mathbf{p}$ & $M \pm m$ & $\mathbf{p}$ \\
\hline Liver cirrhosis & 17 & $23,6 \pm 2,29$ & $<0,05$ & $2,08 \pm 0,179$ & $<0,05$ \\
\hline $\mathrm{CH}, \mathrm{AST}$ norm & 16 & $36,9 \pm 2,05^{*}$ & $>0,05$ & $\mid, 31 \pm 0,067$ & $>0,05$ \\
\hline $\mathrm{CH}, \mathrm{AST}>2$ norm & 13 & $33,0 \pm 3,04 *$ & $>0,05$ & $\mathrm{I}, 34 \pm 0, \mathrm{I} I 0$ & $>0,05$ \\
\hline $\mathrm{CH}, \mathrm{ALT}$ norm & 13 & $37,5 \pm 3,02 *$ & $>0,05$ & $1,35 \pm 0,088$ & $>0,05$ \\
\hline $\mathrm{CH}, \mathrm{ALT}>2$ norm & 21 & $35,9 \pm 2,25 *$ & $>0,05$ & $|, 26 \pm 0,07|$ & $>0,05$ \\
\hline Control & 15 & $31,2 \pm 2,82$ & & $1,22 \pm 0,077$ & \\
\hline
\end{tabular}

Note: $p$ - significant differences with the control $(p<0.05)$; *- Significant differences between liver cirrhosis and chronic hepatitis $(\mathrm{CH})(\mathrm{p}<0.05)$

Dependence between the content of RBP4 and retinol with the 4-th stage of fibrosis (cirrhosis) is fixed. In contrast to chronic hepatitis dependence between the content of RBP4 and 4-th stag is not traced, regardless of the biochemical markers of inflammatory activity in liver.

We think that the development of hyper-retinemia in liver cirrhosis is due to fibrotic evolution and sharp decrease in volume of parenchymal component of liver. And as a result of which the retinol is "washed out" of the HSC because of their degranulation and accumulation of its high level in blood content. This process is associated with a decrease in protein-synthesizing function of liver, which leads to the decrease in the synthesis of RBP4 and its inadequate accumulation in the liver. As a consequence, the deficiency of retinol in liver contributes to the progression of fibrosis.

\section{Conclusions}

Maximum effectiveness of structural and functional evaluation of HSC provides by morphological study of intravital biopsy with simultaneous use of complex cellular imaging techniques (light and electron microscopy of ultrathin sections and original methods of fixation and staining). Results of morphological studies of HSC will improve the quality of intravital diagnosis of fibrosis, to hold its monitoring and prediction of outcomes chronic diffuse liver lesions at a higher level today. Results of morphological findings will help the clinician furtherly include in wording of final diagnosis more accurate data on the chronic stage (stabilization, progression or resolution of fibrosis) in the course of therapy.

\section{Author contributions}

a. V Tsyrkunov: study concept and design, performed experiments, collected data, analyzed and interpreted data, wrote all drafts of the manuscript, and revised the manuscript, study supervision.

b. V Andreev: performed experiments, collected data, wrote all drafts of the manuscript.

c. R Kravchuk: performed experiments, collected data, wrote all drafts of the manuscript.

d. I Kandratovich: performed experiments, collected data, performed statistical analysis, and wrote all drafts of the manuscript.

\section{Conflicts of interest}

The authors have no conflicts of interests related to this publication.

\section{Funding}

None.

\section{References}

1. Brenner DA, Kisseleva T, Scholten D, et al. Origin of myofibroblasts in liver fibrosis. Fibrogenesis Tissue Repair. 2012;5(1):17.

2. Bataller R, Paik YH, Lindquist JN, Lemasters JJ, Brenner DA. Hepatitis C virus core and nonstructural proteins induce fibrogenic effects in hepatic stellate cells. Gastroenterology. 2004;126(2):529-540.

3. Suematsu M, Aiso S. Professor Toshio Ito: a clairvoyant in pericyte biology. Keio J Med. 2001;50(2):66-71.

4. Querner F. Microscopic evidence of vitamin Aimanimal tissue. To note the paraplasmic liver cell inclusions. Third message. Klin Wschr. 1935;14:1213-1217.

5. Senoo H, Kojima N, Sato M. Vitamin A-Storing Cells (Stellate Cells). Vitam Horm. 2007;75:131-159.

6. Popper H. Distribution of vitamin A in tissue as revealed by fluorescence microscopy. Physiol Rev. 1944;24(1):205-224.

7. Serov VV, Severgina LO. [Morphologic criteria for the assessment of etiology, degree of activity and stage of the process in viral chronic hepatitis B and C. Arkh Patol. 1996;58(4):61-64.

8. Sato T, Takagi I. An electron microscopic study of specimen-fixed for longer periods in phosphate buffered formalin. $J$ Electron Microsc. 1982;31(4):423-428.

9. Glauert AM, Glauert RH. Araldite as embedding medium for electron microscopy. J Biophys Biochem Cytol. 1958;4(2):409-414.

10. Millonig GA. Advantages of a phosphate buffer for osmium tetroxide solutions in fixation. $J$ Appl Physics. 1961;32:1637-1643. 
11. Watson ML. Staining of tissue sections for electron microscopy with heavy metals. J Biophys Biochem Cytol. 1958;4(4):475-478.

12. Glauert AM. Fixation, degydratation and embedding of biologica specimens. $1^{\text {st }}$ edn, Practical Methods in Electron Microscopy. New York, USA: American Elsevier; 1975. p. 3.

13. Reynolds ES. The use of lead citrate at high $\mathrm{pH}$ as an electronopaque stain in electron microscopy. J Cell Biol. 1963;17:208-212.

14. Wake K. Hepatic stellate cells: Three-dimensional structure, localization, heterogeneity and development. Proc Jpn Acad Ser B Phys Biol Sci. 2006;82(4):155-164.

15. Lemoinne S, Cadoret A, El Mourabit H, et al. Origins and functions of liver myofibroblasts. Biochim Biophys Acta. 2013;1832(7):948-954.

16. Asahina K, Zhou B, Pu WT, Tsukamoto H. Septum transversumderived mesothelium gives rise to hepatic stellate cells and perivascular mesenchymal cells in developing mouse liver. Hepatology. 2011;53(3):983-995.

17. Scheglev AI, Mishnev OD. Structural and metabolic characteristics of sinusoidal liver cells. Successes Sovr Biol. 1991;3:73-82.

18. Gaga MD. Human and rathepatic stellate cells produce stem cell factor: a possible mechanism for mast cell recruitment in liver fibrosis. $J$ Hepatol. 1999;30(5):850-858.

19. Lyundup AV, Onischenko NA, Krasheninnikov ME, et al. On the role of sinusoidal liver cells and bone marrow cells in ensuring the regenerative strategy of a healthy and damaged liver. Bulletin of Transplantology and Artificial Organs. 2010;12:78-85.

20. Moriwaki H, Blaner WS, Piantedosi R, Goodman DS. Effects of dietary retinoid and triglyceride on the lipid composition of rat liver stellate cells and stellate cell lipid droplets. J Lipid Res. 1988;29(11):1523-1534.

21. Kobold D. Expression of reelin in hepatic stellate cells and during hepatic tissue repair: a novel marker for the differentiation of HSC from other liver myofibroblasts. J Hepatol. 2002;36(5):607-613.

22. Nepomnyaschih GI, Aydagulova SV, Nepomnyaschih DL, et al immunohistochemical study of hepatic stellate cells in the dynamics of infectious - viral genesis fibrosis and cirrhosis of the liver. Bull Exp Biol Med. 2006;142(6):723-738.

23. Wake K, Senoo H. In Cells of the Hepatic Sinusoid. In: Kirn A, Knook DL Wisse E, editors. The Netherlands: Kupffer Cell Foundation, Rijswijk; 1986. p. $215-220$

24. Arthur MJP. Degradation of matrix proteins in liver fibrosis. Pathol Res Pract. 1994;190(9-10):825-833.

25. Ivashkin VT. Klinicheskaya simptomatika dofibroticheskih izmenenij. Stenogramma lekcii Vserossijskogo Internet Kongressa specialistov po Vnutrennim boleznyam, 2013.

26. Pinzani M. PDGF and signal transduction in hepatic stellate cells. Front Biosci. 2002;7:1720-1726.
27. Iredale JP. Hepatic Stellate Cell Behavior During Resolution of Liver Injury. Semin Liver Dis. 2001;21(3):427-436.

28. Safadi R. Immune stimulation of he $\neg$ patic fibrogenesis by CD8 cells and attenuation by trans $\neg$ genic interleukin-10 from hepatocytes. Gastroenterology. 2004;127(3):870-882.

29. Stanciu A, Cotutiu C, Amalinei C. New data about ITO. Rev Med Chir Soc Med Nat Iasi. 2002;107(2):235-239.

30. Friedman S, Rockey D, Montgomery B. Hepatic fibrosis 2006: Report of the Third AASLD Single Topic Conference. Hepatology. 2006;45(1):242249

31. Postnikova OA, Nepomnyaschih DL, Aydagulova SV, et al. Structural and functional characteristics of liver stellate cells in the dynamics of fibrosis. Basic Research. 2011;10:359-362.

32. Marra F, Efsen E, Romanelli RG, et al. Ligands of peroxisome proliferatoractivated receptor gamma $\bmod \neg$ ulateprofibrogenic and proinflammatory actions in hepatic stellate cells. Gastroenterology. 2000;119(2):466-478.

33. Kordes C, Sawitza I, Müller-Marbach A, et al. CD133+ hepatic stellate cells are progenitor cells. Biochem Biophys Res Common. 2007;352(2):410-417.

34. Perepelyuk M, Terajima M, Wang AY, et al. Hepatic stellate cells and portal fibroblasts are the major cellular sources of collagens and lysy oxidases in normal liver and early after injury. Am J Physiol Gastrointest Liver Physiol. 2013;304(6):605-614.

35. Lepreux S, Desmoulière A. Human liver myofibroblasts during development and diseases with a focus on portal (myo) fibroblasts. Front Physiol. 2015;6:173.

36. Paku S, Schnur J, Nagy P, Thorgeirsson SS. Origin and structural evolution of the early proliferating oval cells in rat liver. Am J Hepatol. 2001;158(4):1313-1323.

37. Thabut D, Shah V. Intrahepatic angiogenesis and sinusoidal remodeling in chronic liver disease: new targets for the treatment of portal hypertension? J Hepatol. 2010;53(5):976-980.

38. Chagraoui J, Lepage-Noll A, Anjo A, et al. Fetal liver consists of cells in epithelial-to-mesenchymal transi-tion. Blood. 2003;101(8):2973-2982.

39. Kiyasov AP, Gumerova AA, Titova MA. Oval cells - putative hepatic stem cells or hepatoblasts? Cell Transplantation and Tissue Engineering. 2006;2:55-58.

40. Lukashyk SP, Tsyrkunov VM, Isaykina YI, et al. Mesenchymal Bone Marrow-derived Stem Cells Transplantation in Patients with HCV Related Liver Cirrhosis. J Clin Transl Hepatol. 2014;2(4):217-221.

41. Hinz B, Phan SH, Thannickal VJ, et al. Recent developments in myofibroblast biology: paradigms for connective tissue remodeling. Am J Pathol. 2012;180(4):1340-1355. 